time. One letter from a medical man, we might note, would have been more impressive if the writer had not appended to his not over rare qualifications the style and title " Consultant." The issue may very well be left to the arbitration of time. Meanwhile we would invite the attention of shrewd people to signs already evident of what that arbitration will decree. Nearly every month a paragraph in the newspapers announces the opening or the beginning of some new sanatorium. Queen Alexandra's Institution at Davos has just been given a needed donation of $£ 25,000$, and two sanatoriums in Northumberland more than half that sum. Abroad the same thing happens. Dr. Hermann Biggs told the recent Tuberculosis Conference at Edinburgh, that New York was building a municipal sanatorium for a thousand patients. Let us take an illustration which will appeal to readers of the Christian World. In its early days the Salvation Army came in for hot abuse-much hotter than has ever been bestowed on sanatoriums. Only a few years ago the writer heard imputations of dishonesty on "General " Booth's part made with impunity on a public stage. The highly effective answer this organisation made was to go on growing rapidly. So perhaps in a less degree with the open-air treatment. It is by no means perfect, but it does far more good to the consumptive than anything else has ever done, and therefore, until knowledge makes another advance, it will supplant everything else.

\section{WHO BENEFITS?}

IN our issue of June 25 we called attention to four advertisements which appeared in certain morning papers, each acknowledging a five-pound banknote from an appeal in a weekly newspaper. The paper which has adopted this method of advertising itself asks us, through its manager, to state that it is the Gentlewoman. He seems oblivious or indifferent to the fact that the plan pursued may deceive the public into thinking that such advertisements are inserted by the managers of the charities mentioned. If they had been so inserted it is clear, as we pointed out, that the expense of these advertisements in two morning papers only at the published scale rate of these papers was $£ 717 \mathrm{~s}$. $6 \mathrm{~d}$., or nearly 40 per cent. of the $£ 20$ advertised. The giving public is aware of the cost of advertisements, and it is not just to any hospital that advertisements of this kind acknowledging small gifts should be inserted at the secret expense of a newspaper or other advertiser. In the present case the Gentlewoman clearly gets the chief benefit of such advertisements. If the Gentlewoman wishes to advertise itself, and the managers of a public charity choose to lend their name to enable it to do so, every such advertisement should contain a clear statement of the fact. Most hospitals of any standing would, however, decline to lend their name to any advertiser for such a purpose. This is made clear by a letter published in another column, which we have received from a hospital secretary, who no doubt voices the general opinion of hospital managers on the point.

\section{THE DRUG MARKET.}

Business in drugs and chemicals has been slightly better during the week, although it cannot by any means be called good. As had been expected, manufacturers of codeine have reduced their prices by $8 d$. per ounce; morphine also tends lower. The opium market is still quiet, and buyers are hoping that prices will further recede as the new crop continues to come on the market. Buchu leaves are again dearer, and at present there appears to be no prospect of a decline in value. Menthol is dearer and in good demand. Ergot is tending higher in price. Linseed is dearer, with an advancing tendency. Cocaine is unaltered in price, but an advance is not improbable. Rhubarb is slightly lower in value. The expected advance in the price of potassium bromide and sodium bromide has not yet taken place.

\section{APPOINTMENTS.}

Hubert Pinto-Leite, B.A. Cantab, M.R.C.S., L.R.C.P., has been appointed Clinical Assistant at the Royal London Ophthalmic Hospital, and re-appointed Clinical Assistant to the Aural Department at St. George's Hospital.

\section{OBITUARY.}

The late Colonel Leslie Ogilby Patterson, of the Army Medical Service, whose death is announced, qualified as a member of the Royal College of Surgeons of England in 1851 and joined the Army in 1854. He served in the Burmese War in 1856, and was present at several actions during the Indian Mutiny, Jugdispur, and was wounded at Sirchooa. He was mentioned in despatches, awarded the Mutiny medal, and retired in 1880 with the honorary rank of Brigade-Surgeon. $\mathrm{He}$ had been at one time a surgeon to the Royal Canadian Rifle Regiment and a surgeonmajor to the Royal Artillery.

An inquest was held at Westgate last week on Mr. John Bart Rous, who died from morphia poisoning at the age of thirty-one. Mr. Rous, who was on the editorial staff of the Lancet, took his diploma in 1903, having studied at St. Mary's Hospital. Here he was afterwards house physician, having graduated M.B., B.S., with honours at London University in 1904. His appointments included that of R.M.O. at Hampstead General Hospital and of house surgeon to the East Sussex Hcspital. Then he devoted himself to medical journalism. Recently he had resigned from the R.A.M.C. owing to ill-health. A verdict of "Suicide during temporary insanity" was returned.

THE death is announced of Mr. Robert Grant, C.B., M.B., M.A., Inspector-General of Hespitals and Fleets,' R.N. (retired), at the age of sixty-eight. He studied at the University of Aberdeen, where he graduated M.B., B.S., in 1866. In 1868 he joined the Navy, and served in the Zulu and Kaffir Wars of 1877-9, having charge of the hospital ship at Capetown during an outbreak of smallpox. For this he received a medal and promotion. He served in the Egyptian War of 1882, and gained the Khedive's Bronze Star. In 1888 he became Fleet-Surgeon, Deputy Inspector-General in 1897, and Inspector-General in 1901. He received the C.B. at King Edward's coronation. 